\title{
Differential Survival between Visual Environments Supports a Role of Divergent Sensory Drive in Cichlid Fish Speciation
}

\author{
Martine E. Maan, ${ }^{1,2, \star}$ Ole Seehausen, ${ }^{2}$ and Ton G. G. Groothuis ${ }^{1}$ \\ 1. Groningen Institute for Evolutionary Life Sciences, University of Groningen, PO Box 11103, 9700 CC Groningen, The Netherlands; \\ 2. Center for Ecology, Evolution and Biogeochemistry, Eawag Federal Institute of Aquatic Science and Technology, Seestrasse 79, 6074 \\ Kastanienbaum, Switzerland; and Institute for Ecology and Evolution, University of Bern, Baltzerstrasse 6, 3012 Bern, Switzerland
}

Submitted April 6, 2016; Accepted September 14, 2016; Electronically published November 30, 2016

Online enhancements: appendix. Dryad data: http://dx.doi.org/10.5061/dryad.6nh3j.

\begin{abstract}
AвSTRACT: Identifying the selective forces that initiate ecological speciation is a major challenge in evolutionary biology. Sensory drive has been implicated in speciation in various taxa, largely based on phenotype-environment correlations and signatures of selection in sensory genes. Here, we present a reciprocal transplant experiment revealing species differences in performance in alternative visual environments, consistent with speciation by divergent sensory drive. The closely related cichlids Pundamilia pundamilia and Pundamilia nyererei inhabit different visual environments in Lake Victoria and show associated differences in visual system properties. Mimicking the two light environments in the laboratory, we find a substantial reduction in survival of both species when reared in the other species' visual environment. This implies that the observed differences in Pundamilia color vision are indeed adaptive and substantiates the implicit assumption in sensory drive speciation models that divergent environmental selection is strong enough to drive divergence in sensory properties.
\end{abstract}

Keywords: mortality, visual adaptation, experiment, fitness, reciprocal transplant, Lake Victoria, Pundamilia.

\section{Introduction}

According to ecological speciation theory, divergent adaptation to alternative ecological opportunities can initiate reproductive isolation between diverging populations and, eventually, speciation (Endler 1977; Schluter 2000; Nosil 2012). Both the initiation and persistence of divergent ecotypes require that each has a fitness advantage over the other in their own niche. This fitness advantage is reflected

\footnotetext{
* Corresponding author; e-mail: m.e.maan@rug.nl.

ORCIDs: Maan, http://orcid.org/0000-0003-1113-8067; Seehausen, http:// orcid.org/0000-0001-6598-1434.

Am. Nat. 2017. Vol. 189, pp. 78-85. (C) 2016 by The University of Chicago. 0003-0147/2017/18901-56913\$15.00. All rights reserved. This work is licensed under a Creative Commons Attribution-NonCommercial 4.0 International License (CC BY-NC 4.0), which permits non-commercial reuse of the work with attribution. For commercial use, contact journalpermissions@press.uchicago.edu. DOI: $10.1086 / 689605$
}

in the nonrandom distribution of these ecotypes (or trait values) across (micro)habitats. Perhaps the strongest evidence for divergent adaptation comes from reciprocal transplant experiments, in which ecotypes or incipient species are shown to suffer reduced fitness in each other's environment. Such experiments have shown that adaptive divergence can happen fast and at small spatial scales (e.g., Schluter 1995; Bongaerts et al. 2011; Westley et al. 2013; Moser et al. 2016; Soudi et al. 2016).

However, reduced fitness in the nonnative niche, as observed in nature or in reciprocal transplant experiments, can be caused by various selective forces acting simultaneously. Ecological niches are multidimensional: habitats can differ in spatial location, climatic conditions, food resources, predator and parasite communities, and sensory conditions (Maan and Seehausen 2011). The importance of this multidimensionality of selection in the different stages of speciation, relative to the contribution of strong selection along a single axis of differentiation, remains an open question in speciation biology (Nosil et al. 2009; Seehausen et al. 2014).

Experimental manipulation of selective agents can be instrumental in identifying the ecological cause of divergence. Here, we present a reciprocal transplant experiment in cichlid fish, in which manipulation of a single environmental variable, the visual environment, causes substantial fitness effects.

Several recent studies have reported evidence for a role of sensory drive in speciation: the idea that divergent sensory adaptation to different sensory environments contributes to, or even initiates, the evolution of reproductive isolation between diverging populations (Endler 1992; Boughman 2002). As sensory perception is critical to both survival and reproduction, sensory systems must adapt to a multitude of sensory challenges associated with navigation, detecting food, avoiding enemies, and evaluating potential mates_-generating a large diversity in sensory 
abilities across the animal kingdom. The most convincing evidence for divergent sensory drive comes from studies in fish, probably because aquatic environments provide pronounced heterogeneity in visual conditions (e.g., Boughman 2001; Fuller et al. 2005; Seehausen et al. 2008; Kekalainen et al. 2010; Morrongiello et al. 2010; Chang et al. 2015).

Cichlid fish form one of the most species-rich families of vertebrates, with more than 2,000 species inhabiting tropical rivers and lakes (Kocher 2004). The haplochromine lineage, in particular, underwent multiple adaptive radiations in African lakes, constituting an exceptionally rewarding model system for speciation research (Salzburger et al. 2005; Seehausen 2006; Wagner et al. 2012). Speciation in haplochromines is associated with divergence in water depth habitat, sensory perception, sexual communication traits, feeding morphology, and behavior (Seehausen 2015). Currently, evidence is accumulating that visual adaptation to different underwater light conditions, mediated by water depth and turbidity, plays a key role in haplochromine speciation: the lineage shows extensive variation in color vision properties, which is associated with variation in visual habitat and sexual signaling (Seehausen et al. 1997; Carleton et al. 2005; Spady et al. 2005; Hofmann et al. 2009; Miyagi et al. 2012). In Lake Victoria Pundamilia cichlids, species divergence in visual pigment genes precedes the accumulation of differentiation at neutral loci, suggesting that divergent visual adaptation may be leading the speciation process (Seehausen et al. 2008). Here, we investigate experimentally the fitness consequences of divergent visual adaptation in two Pundamilia sister species, by measuring survival in two distinct light environments. We also include interspecific hybrids, predicting intermediate responses and possibly lower fitness.

\section{Methods \\ Fish}

Pundamilia pundamilia and Pundamilia nyererei are two closely related species that co-occur at several locations in Lake Victoria (Seehausen 2009). At all of these, P. nyererei breeds in deeper waters than $P$. pundamilia. Due to the rapid absorbance of short wavelengths (violet, blue) in Lake Victoria, the deeper habitat of $P$. nyererei has a red-shifted, yellowish light spectrum, while $P$. pundamilia experiences a broad daylight spectrum (Lythgoe 1984; Seehausen et al. 1997; Maan et al. 2006). This environmental difference coincides with species differences in visual pigment gene sequences and expression (Carleton et al. 2005; Seehausen et al. 2008), as well as behavioral responses to blue and red light (Maan et al. 2006). Male nuptial coloration and female mate preferences have diverged in parallel: P. pundamilia females prefer the blue coloration of $P$. pundamilia males, while $P$. nyererei females prefer the yellow and red coloration of $P$. nyererei males (Seehausen and Van Alphen 1998; Selz et al. 2014), indicating that divergent visual adaptation may directly or indirectly affect sexual communication and reproductive isolation (Maan and Seehausen 2010).

Fish were collected in 2010 at Python Islands in the Mwanza Gulf (Lake Victoria, -2.6237, 32.8567). In this population, $P$. pundamilia and $P$. nyererei are considered incipient species that occasionally hybridize (Seehausen 2009). Fish were collected by angling (0.5-1.5 m water depth) and by gill nets (2-7 $\mathrm{m} ; P$. nyererei only).

\section{Housing and Breeding}

Wild-caught fish were identified with PIT tags (Passive Integrated Transponder, Biomark, ID, and Dorset Identification, Aalten, Netherlands). A total of 31 parental individuals generated $23 \mathrm{~F}_{1}$ families, with several individuals spawning more than once (table A1; tables A1, A2 are available online). The experiment started in the aquarium facility of the Eawag Center for Ecology, Evolution and Biogeochemistry in Kastanienbaum (Switzerland), where the majority of clutches were produced ( $n=16$; December 2010-September 2011). Due to the relocation of one of the authors (M. E. Maan), fish were moved to the University of Groningen (Netherlands) in September 2011, where seven more clutches were born. Survival rates did not differ between locations $(P>.7$ for both 6-month and 12-month survival), but to account for potential effects, we included proportion of time spent in Switzerland as a fixed effect in all statistical models.

Parental fish were kept in a recirculation aquarium facility $\left(24.5^{\circ} \pm 1^{\circ} \mathrm{C}\right)$ illuminated with fluorescent tube lights (12L:12D). Fish were fed twice a day. Adult fish were fed 6 days a week, with a mixture of commercial pellets and flakes, as well as defrosted frozen food (containing krill, shrimp, peas, spirulina, black mosquito larvae, and Artemia). Females were housed in single-species groups, together with a single male of either species. As all haplochromines, Pundamilia are female mouthbrooders: after spawning, females keep the offspring in their mouths for about 3 weeks. Here, to minimize exposure to fluorescent light, offspring were removed from the mother's mouth at approximately 6 days after spawning (mean \pm SE: $6.3 \pm 0.5$ days postfertilization [dpf]; eggs hatch at about 5-6 dpf). Clutches were then divided over two rearing containers, one of which was placed in the shallow light condition and the other in the deep light condition (see below). Fry were released into aquaria (25$100 \mathrm{~L}$ ) once they reached free-swimming stage ( 3 weeks). Fry were fed twice a day (once a day on weekends) with commercial flake food, ground to fine powder for the first few weeks. 


\section{Light Conditions}

Light treatments were based on the natural light environments experienced by $P$. pundamilia and $P$. nyererei at Python Islands (fig. A1; figs. A1-A4 are available online), measured with a BLK-C-100 spectrophotometer and an F-600-UV-VIS-SR optical fiber with CR2 cosine receptor (Stellar-Net, FL). For details, see the appendix, available online. Both treatments employed halogen lights (Philips Masterline ES, $30 \mathrm{~W}$ and $35 \mathrm{~W}$ ) filtered with a green filter (no. 243 by LEE, Andover, UK). In the shallow light condition, blue lights (Paulmann 88090 ESL Blue Spiral 15 W) were added to compensate for the low short-wavelength radiance of the halogen lights. In the deep light condition, short-wavelength light was reduced by adding a yellow filter (LEE no. 15). The resulting downwelling irradiance was measured with the same equipment as in the field. To verify the resemblance between natural and laboratory light conditions for the wavelengths that are most relevant for the Pundamilia visual system, we estimated the proportion of incident light captured by the three main photopigments of Pundamilia, for both lab and field spectra (see appendix). This showed that in both field and laboratory conditions, the deep light condition generates lower short-wavelength-sensitive (SWS) and higher long-wavelength-sensitive (LWS) light capture than the shallow light condition, with laboratory conditions slightly exaggerating the differences in nature. We did not attempt to also mimic the light intensity differences between shallow and deep habitats, because these are much smaller than the rapid intensity variations produced by changes in cloud cover ( $>1,000$-fold) and unlikely to affect visual development or performance.

\section{Data Collection}

Fish were counted at irregular intervals. This is because they were bred for other purposes than documenting survival differences between groups - the results reported here emerged serendipitously from counts that were conducted for administrative purposes only; we did not expect any differences in survival between the groups. On average, numbers of individuals in each clutch and in each light treatment were determined every 2 months. Based on these counts, survival was estimated at 6 and 12 months of age. As fish started to become sexually mature (from 9 months onward), individuals of some of the smaller clutches were housed individually because in small groups $(n<7)$, aggressive interactions may lead to the death of subdominant individuals. We did not keep record of this, but it affected fewer than $25 \%$ of the groups and only the final weeks of the observation period. Moreover, this intervention was conservative with respect to testing the hypothesis that visual system differences are adaptive. This is because individual housing increases sur- vival and was implemented in the smallest groups only, thus augmenting the survival of fish reared in mismatched light conditions and reducing the fitness consequences of maladaptation.

\section{Analysis}

All analyses were conducted in R (ver. 3.3.1; R Development Core Team 2016). We used generalized linear mixed effects models with binomial distribution and logit link function (library lme4). As a dependent variable, we used the raw counts of live and dead fish in each family, combined with the cbind function. As fixed effects, we analyzed light treatment (shallow and deep light conditions) and species ( $P$. pundamilia, $P$. nyererei, and $\mathrm{F}_{1}$ hybrids). Hybrids from the reciprocal crosses $(P$. pundamilia mother and $P$. nyererei father, or vice versa) were pooled into a single hybrid category for the analysis, because they did not differ in survival (see appendix). All models included time spent in Switzerland as a fixed effect (see above), random effects for mother and father identity to account for family structure, and a random effect at the level of observation to correct for overdispersion. Statistical significance of fixed effects (and their interactions) was established by log-likelihood tests on nested models; adjusted $P$ values for the observed differences between groups were obtained by post hoc tests (Tukey's honest significant difference [HSD]; library multcomp). Model structure is given in the appendix.

\section{Results}

Overall survival was $74.8 \% \pm 3.2 \%$ at 6 months and $51.7 \% \pm 3.3 \%$ at 12 months. There were no overall differences in survival between light treatments (deep vs. shallow; $\chi_{6,1}^{2}=<1.90, P>.17$ for both time points) or between species ( $P$. pundamilia, $P$. nyererei, or hybrid; $\chi_{7,2}^{2} \leq 1.43, P \geq$ $.49)$.

As illustrated in figure 1, there was a significant species $\times$ treatment interaction effect on both 6- and 12-month survival (6 months: $\chi_{10,2}^{2}=6.24, P=.044 ; 12$ months: $\chi_{1,2}^{2}=$ 20.75, $P<.0001)$ : both $P$. pundamilia and $P$. nyererei survived better in the light condition that mimicked their natural light environment. At 6 months, post hoc comparisons between light conditions for each species separately were not significant (Tukey's HSD: all $P>.1$ ), but at 12 months, $P$. pundamilia survived significantly better in the shallow light condition $(z=3.24, P=.013)$, while $P$. nyererei survived better in the deep light condition $(z=-3.97, P<$ $.001)$. Hybrid survival did not differ between light conditions at either time point $(z>-2.30, P>.18)$.

Hybrid survival was not different from that of either parental species in its native habitat: in deep light conditions, hybrids and $P$. nyererei survived at similar rates (Tukey's 

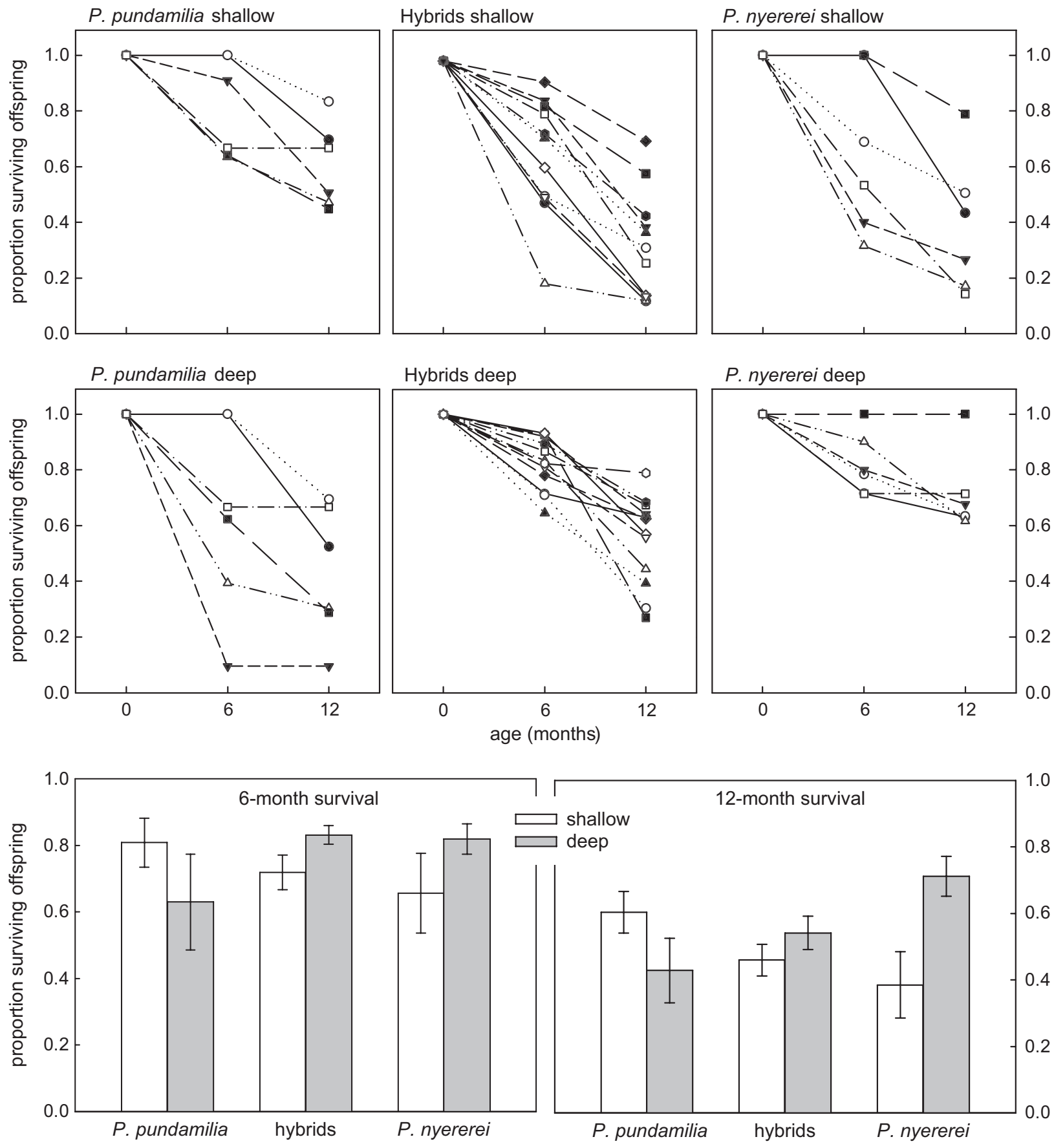

Figure 1: Survival of $\mathrm{F}_{1}$ offspring of Pundamilia pundamilia, Pundamilia nyererei, and hybrids under light conditions mimicking those in shallow and deep water in Lake Victoria. Top six panels, proportion of surviving offspring at 6 and 12 months in the shallow condition (upper panels) and deep condition (lower panels). Each symbol/line combination represents a family. Bottommost panels, averages across families.

HSD: $P>.5$ ), and the same was true for hybrids and $P$. pundamilia in the shallow habitat $(P>.3)$. Expanded model output is given in the appendix; data are deposited in the Dryad Digital Repository: http://dx.doi.org/10.5061/dryad $.6 \mathrm{nh} 3 \mathrm{j}$ (Maan et al. 2017).

\section{Discussion}

Sensory adaptation has been implicated in speciation in a variety of taxa, particularly in aquatic organisms (Boughman 2002). This is largely based on correlations between 
variation in visual environments and variation in fish visual properties (e.g., Carleton et al. 2005; Fuller et al. 2005; Davies et al. 2009; Hofmann et al. 2009) and signatures of selection on visual pigment genes (e.g., Terai et al. 2006; Hofmann et al. 2009, 2012; Larmuseau et al. 2010; Weadick et al. 2012; Tezuka et al. 2014; Gaither et al. 2015; TorresDowdall et al. 2015). Some of the strongest evidence comes from populations of the Lake Victoria cichlids Pundamilia pundamilia and Pundamilia nyererei, in which the extent of depth segregation between these two species, causing exposure to different visual environments, correlates with the extent of divergence in visual properties, visual communication traits, and reproductive isolation (Seehausen et al. 2008). Here, we present the first experimental evidence that these species differences in visual perception affect fitness in alternative visual environments, a prerequisite for the operation of divergent sensory drive.

Mimicking the two light environments in the laboratory, and rearing both species in both of these, we found that the survival of both $P$. pundamilia and $P$. nyererei was substantially reduced when reared in the other species' visual environment (taking both species together: $37 \%$ at 12 months). This finding validates the implicit assumption in sensory drive speciation models that divergent environmental selection is strong enough to drive divergence in sensory properties and suggests that the observed differences in Pundamilia color vision are indeed adaptive. It also implies a trade-off between visual performance in alternative environments. Indeed, $P$. pundamilia and $P$. nyererei carry different alleles for the LWS visual pigment, which corresponds to a red-shifted peak sensitivity in P. nyererei (Carleton et al. 2005; Seehausen et al. 2008). Pundamilia nyererei also has a higher abundance of red-sensitive cones in the retina (Carleton et al. 2005) and a stronger behavioral sensitivity to red light (Maan et al. 2006). Comparison of Pundamilia populations at different stages of divergence suggests that the evolution of these differences preceded the accumulation of neutral differentiation (Seehausen et al. 2008), indicating that divergent visual adaptation has been important during the initial stages of Pundamilia speciation.

The mechanism underlying the observed species $\times$ light interaction requires further study. Possibly, fish were less efficient at detecting and capturing food in unfavorable light regimes. Effects of spectral conditions on foraging performance have been documented in a variety of aquatic organisms (e.g., newts [Martin et al. 2016], killifish [Fuller et al. 2010], stickleback [Rick et al. 2012], guppies [White et al. 2005]). In addition, unfavorable light conditions can be stressful to fish (Volpato and Barreto 2001; Migaud et al. 2007; Karakatsouli et al. 2015) and exert species-specific effects on aggression levels (Holtby and Bothwell 2008; Carvalho et al. 2013). Together, these factors may have caused increased mortality. Specifically, we observed, but did not quantify, depensatory growth: a common phenomenon in fish where size differences between individuals increase with time, often resulting in reduced survival of the smaller fish (Magnuson 1962; Fernandes and Volpato 1993; Baras and Jobling 2002). We did not document fish growth, but we suggest that food competition and/or (social) stress accelerated depensatory growth and mortality in the fish that were reared in unnatural light conditions.

We did not observe light-specific mortality in hybrids. Assuming that hybrid visual perception is intermediate between the two parental species (Carleton et al. 2010), this finding is consistent with the hypothesis that environmentdependent survival is due to genetic variation in visual system properties. It is also consistent with earlier studies on hybrid viability (Van der Sluijs et al. 2008) and with the observation that hybrids indeed occur at Python Islands (Seehausen et al. 2008). However, it also implies that visual adaptation does not cause reduced hybrid fitness. This means that the difference in light conditions between shallow and deep waters alone, independent of other ecological factors not addressed here, may not generate disruptive selection and thus not promote reproductive isolation between $P$. pundamilia and $P$. nyererei.

The contribution of divergent visual adaptation to Pundamilia speciation may be mediated by two other, not mutually exclusive mechanisms. First, reduced foraging success and/or increased stress in unfavorable visual conditions may stimulate individuals to move toward visual environments where they do better, resulting in adaptive habitat matching (Edelaar et al. 2008). Assortative mating could then emerge as an immediate by-product of depth segregation. Second, female $P$. pundamilia and $P$. nyerere exert species-assortative mating preferences that are mediated by male coloration (Seehausen and Van Alphen 1998; Selz et al. 2014). These preferences may be influenced directly by visual adaptation: a general preference for conspicuous males, as documented in these and other haplochromine cichlids (Maan and Sefc 2013), would translate to different color preferences when visual adaptation affects the perceived conspicuousness of different colors (Endler 1992; Boughman 2002; Maan et al. 2006; Seehausen et al. 2008).

Gene $\times$ environment interactions in the context of visual performance may be common in aquatic taxa. Fish visual systems have been shown to respond plastically to environmental variation (Fuller et al. 2005; Shand et al. 2008), influencing visually guided behaviors such as foraging and mate choice (Fuller and Noa 2010; Fuller et al. 2010). Also in cichlids, the expression of retinal pigments and different photoreceptors changes in response to the light conditions during development (Van der Meer 1993; Smith et al. 2012), but some species show stronger responses than others (Hofmann et al. 2010). The data presented here suggest that Pundamilia may express limited plasticity and/or that 
the plastic response is not sufficient to compensate for the genetically determined species differences in visual development.

To conclude, our results indicate that selection against phenotype-environment mismatched individuals could contribute to reproductive isolation between cichlid populations adapting to different visual conditions, thereby providing experimental support for speciation by sensory drive in Pundamilia. Visual pigment variation in other cichlid species suggests that this could be a widespread phenomenon, contributing to the rapid speciation in this family (Brawand et al. 2014). Future work will be aimed at unravelling the underlying mechanisms, to establish the causal link between species-specific genetic variation and its environment-specific effects on individual behavior and physiology as well as the consequences for reproductive isolation.

\section{Acknowledgments}

We acknowledge the Tanzanian Commission for Science and Technology for research permission and the Tanzanian Fisheries Research Institute for hospitality and facilities. We thank M. Haluna, M. Kayeba, E. Ripmeester, and O. Selz for help in the field and D. Dagani, E. Schaeffer, J. Schuler, A. Taverna, S. Veenstra, and B. Verbeek for taking care of the fish in the laboratory. Insightful comments by R. Fuller and two anonymous referees improved the manuscript. Financial support came from the Swiss National Science Foundation (SNSF PZ00P3-126340 to M.E.M.) and the Netherlands Foundation for Scientific Research (NWO VENI 863-009-005 to M.E.M.).

\section{Literature Cited}

Baras, E., and M. Jobling. 2002. Dynamics of intracohort cannibalism in cultured fish. Aquaculture Research 33:461-479.

Bongaerts, P., C. Riginos, K. B. Hay, M. J. H. van Oppen, O. HoeghGuldberg, and S. Dove. 2011. Adaptive divergence in a scleractinian coral: physiological adaptation of Seriatopora hystrix to shallow and deep reef habitats. BMC Evolutionary Biology 11:303.

Boughman, J. W. 2001. Divergent sexual selection enhances reproductive isolation in sticklebacks. Nature 411:944-948.

2002. How sensory drive can promote speciation. Trends in Ecology and Evolution 17:571-577.

Brawand, D., C. E. Wagner, Y. I. Li, M. Malinsky, I. Keller, S. Fan, O. Simakov, et al. 2014. The genomic substrate for adaptive radiation in African cichlid fish. Nature 513:375-381.

Carleton, K. L., C. M. Hofmann, C. Klisz, Z. Patel, L. M. Chircus, L. H. Simenauer, N. Soodoo, R. C. Albertson, and J. R. Ser. 2010. Genetic basis of differential opsin gene expression in cichlid fishes. Lournal of Evolutionary Biology 23:840-853.

Carleton, K. L., J. W. L. Parry, J. K. Bowmaker, D. M. Hunt, and O. Seehausen. 2005. Colour vision and speciation in Lake Victoria cichlids of the genus Pundamilia. Molecular Ecology 14:43414353 .
Carvalho, T. B., F. Z. Mendonca, R. S. Costa-Ferreira, and E. Goncalves-de-Freitas. 2013. The effect of increased light intensity on the aggressive behavior of the Nile tilapia, Oreochromis niloticus (Teleostei: Cichlidae). Zoologia 30:125-129.

Chang, C., Y. T. Shao, W. Fu, K. Anraku, Y. Lin, and H. Y. Yan. 2015. Differentiation of visual spectra and nuptial colorations of two Paratanakia himantegus subspecies (Cyprinoidea: Acheilognathidae) in response to the distinct photic conditions of their habitats. Zoological Studies 54:43.

Davies, W. L., S. P. Collin, and D. M. Hunt. 2009. Adaptive gene loss reflects differences in the visual ecology of basal vertebrates. Molecular Biology and Evolution 26:1803-1809.

Edelaar, P., A. M. Siepielski, and J. Clobert. 2008. Matching habitat choice causes directed gene flow: a neglected dimension in evolution and ecology. Evolution 62:2462-2472.

Endler, J. A. 1977. Geographic variation, speciation, and clines. Princeton University Press, Princeton, NJ.

. 1992. Signals, signal conditions, and the direction of evolution. American Naturalist 139(suppl.):S125-S153.

Fernandes, M., and G. Volpato. 1993. Heterogeneous growth in the Nile tilapia: social stress and carbohydrate metabolism. Physiology and Behavior 54:319-323.

Fuller, R. C., K. L. Carleton, J. M. Fadool, T. C. Spady, and J. Travis. 2005. Genetic and environmental variation in the visual properties of bluefin killifish, Lucania goodei. Journal of Evolutionary Biology 18:516-523.

Fuller, R. C., and L. A. Noa. 2010. Female mating preferences, lighting environment, and a test of the sensory bias hypothesis in the bluefin killifish. Animal Behaviour 80:23-35.

Fuller, R. C., L. A. Noa, and R. S. Strellner. 2010. Teasing apart the many effects of lighting environment on opsin expression and foraging preference in bluefin killifish. American Naturalist 176: $1-13$.

Gaither, M. R., M. A. Bernal, R. R. Coleman, B. W. Bowen, S. A. Jones, W. B. Simison, and L. A. Rocha. 2015. Genomic signatures of geographic isolation and natural selection in coral reef fishes. Molecular Ecology 24:1543-1557.

Hofmann, C. M., N. J. Marshall, K. Abdilleh, Z. Patel, U. E. Siebeck, and K. L. Carleton. 2012. Opsin evolution in damselfish: convergence, reversal, and parallel evolution across tuning sites. Lournal of Molecular Evolution 75:79-91.

Hofmann, C. M., K. E. O'Quin, N. J. Marshall, T. W. Cronin, O. Seehausen, and K. L. Carleton. 2009. The eyes have it: regulatory and structural changes both underlie cichlid visual pigment diversity. PLoS Biology 7:e1000266.

Hofmann, C. M., K. E. O'Quin, A. R. Smith, and K. L. Carleton. 2010. Plasticity of opsin gene expression in cichlids from Lake Malawi. Molecular Ecology 19:2064-2074.

Holtby, L. B., and M. L. Bothwell. 2008. Effects of solar ultraviolet radiation on the behaviour of juvenile coho salmon (Oncorhynchus kisutch): avoidance, feeding, and agonistic interactions. Canadian Journal of Fisheries and Aquatic Sciences 65:701-711.

Karakatsouli, N., N. Kassianos, and S. E. Papoutsoglou. 2015. Effects of rearing density and tank colour on juvenile sharpsnout seabream (Diplodus puntazzo) growth performance. Aquaculture International 23:943-953.

Kekalainen, J., H. Huuskonen, V. Kiviniemi, and J. Taskinen. 2010. Visual conditions and habitat shape the coloration of the Eurasian perch (Perca fluviatilis L.): a trade-off between camouflage and communication? Biological Journal of the Linnean Society 99:47-59. 
Kocher, T. 2004. Adaptive evolution and explosive speciation: the cichlid fish model. Nature Reviews Genetics 5:288-298.

Larmuseau, M. H. D., T. Huyse, K. Vancampenhout, J. K. J. Van Houdt, and F. A. M. Volckaert. 2010. High molecular diversity in the rhodopsin gene in closely related goby fishes: a role for visual pigments in adaptive speciation? Molecular Phylogenetics and Evolution 55:689-698.

Lythgoe, J. N. 1984. Visual pigments and environmental light. Vision Research 24:1539-1550.

Maan, M. E., K. D. Hofker, J. J. M. van Alphen, and O. Seehausen. 2006. Sensory drive in cichlid speciation. American Naturalist 167:947-954.

Maan, M. E., and O. Seehausen. 2010. Mechanisms of species divergence through visual adaptation and sexual selection: perspectives from a cichlid model system. Current Zoology 56:285-299.

- 2011. Ecology, sexual selection and speciation. Ecology Letters 14:591-602.

Maan, M. E., O. Seehausen, and T. G. G. Groothuis. 2017. Data from: Differential survival between visual environments supports a role of divergent sensory drive in cichlid fish speciation. American Naturalist, Dryad Digital Repository, http://dx.doi.org/10.5061/dryad $.6 \mathrm{nh} 3 \mathrm{j}$.

Maan, M. E., and K. M. Sefc. 2013. Colour variation in cichlid fish: developmental mechanisms, selective pressures and evolutionary consequences. Seminars in Cell and Developmental Biology 24 516-528.

Magnuson, J. 1962. An analysis of aggressive behavior, growth and competition for food and space in Medaka (Oryzias Latipes (Pisces, Cyprinodontidae)). Canadian Journal of Zoology 40:313-363.

Martin, M., M. Thery, G. Rodgers, D. Goven, S. Sourice, P. Mege, and J. Secondi. 2016. UV wavelengths experienced during development affect larval newt visual sensitivity and predation efficiency. Biology Letters 12:20150954.

Migaud, H., M. Cowan, J. Taylor, and H. W. Ferguson. 2007. The effect of spectral composition and light intensity on melatonin, stress and retinal damage in post-smolt Atlantic salmon, Salmo salar. Aquaculture 270:390-404.

Miyagi, R., Y. Terai, M. Aibara, T. Sugawara, H. Imai, H. Tachida, S. I. Mzighani, T. Okitsu, A. Wada, and N. Okada. 2012. Correlation between nuptial colors and visual sensitivities tuned by opsins leads to species richness in sympatric Lake Victoria cichlid fishes. Molecular Biology and Evolution 29:3281-3296.

Morrongiello, J. R., N. R. Bond, D. A. Crook, and B. B. M. Wong. 2010. Nuptial coloration varies with ambient light environment in a freshwater fish. Journal of Evolutionary Biology 23:2718-2725.

Moser, D., A. Frey, and D. Berner. 2016. Fitness differences between parapatric lake and stream stickleback revealed by a field transplant. Journal of Evolutionary Biology 29:711-719.

Nosil, P. 2012. Ecological speciation. Oxford University Press, New York.

Nosil, P., L. J. Harmon, and O. Seehausen. 2009. Ecological explanations for (incomplete) speciation. Trends in Ecology and Evolution 24:145-156.

R Development Core Team. 2016. R: a language and environment for statistical computing, Vienna.

Rick, I. P., D. Bloemker, and T. C. M. Bakker. 2012. Spectral composition and visual foraging in the three-spined stickleback (Gasterosteidae: Gasterosteus aculeatus L.): elucidating the role of ultraviolet wavelengths. Biological Journal of the Linnean Society 105: 359-368.
Salzburger, W., T. Mack, E. Verheyen, and A. Meyer. 2005. Out of Tanganyika: genesis, explosive speciation, key-innovations and phylogeography of the haplochromine cichlid fishes. BMC Evolutionary Biology 5.

Schluter, D. 1995. Adaptive radiation in sticklebacks: trade-offs in feeding performance and growth. Ecology 76:82-90.

2000. The ecology of adaptive radiation. Oxford University Press, Oxford.

Seehausen, O. 2006. African cichlid fish: a model system in adaptive radiation research. Proceedings of the Roval Societv B 273:1987-1998. 2009. Progressive levels of trait divergence along a "speciation transect" in the Lake Victoria cichlid fish Pundamilia. Pages 155-176 in R. K. Butlin, D. Schluter, and J. R. Bridle, eds. Speciation and patterns of diversity. Cambridge University Press, New York.

- 2015. Process and pattern in cichlid radiations - inferences for understanding unusually high rates of evolutionary diversification. New Phytologist 207:304-312.

Seehausen, O., R. K. Butlin, I. Keller, C. E. Wagner, J. W. Boughman, P. A. Hohenlohe, C. L. Peichel, et al. 2014. Genomics and the origin of species. Nature Reviews Genetics 15:176-192.

Seehausen, O., Y. Terai, I. S. Magalhaes, K. L. Carleton, H. D. J. Mrosso, R. Miyagi, I. Van der Sluijs, et al. 2008. Speciation through sensory drive in cichlid fish. Nature 455:620-626.

Seehausen, O., and J. J. M. Van Alphen. 1998. The effect of male coloration on female mate choice in closely related Lake Victoria cichlids (Haplochromis nyererei complex). Behavioral Ecology and Sociobiology 42:1-8.

Seehausen, O., J. J. M. Van Alphen, and F. Witte. 1997. Cichlid fish diversity threatened by eutrophication that curbs sexual selection. Science 277:1808-1811.

Selz, O. M., M. E. R. Pierotti, M. E. Maan, C. Schmid, and O. Seehausen. 2014. Female preference for male color is necessary and sufficient for assortative mating in 2 cichlid sister species. Behavioral Ecology 25:612-626.

Shand, J., W. L. Davies, N. Thomas, L. Balmer, J. A. Cowing, M. Pointer, L. S. Carvalho, et al. 2008. The influence of ontogeny and light environment on the expression of visual pigment opsins in the retina of the black bream, Acanthopagrus butcheri. ology 211:1495-1503.

Smith, A. R., K. Ma, D. Soares, and K. L. Carleton. 2012. Relative LWS cone opsin expression determines optomotor thresholds in Malawi cichlid fish. Genes, Brain and Behavior 11:185-192.

Soudi, S., K. Reinhold, and L. Engqvist. 2016. Ecologically dependent and intrinsic genetic signatures of postzygotic isolation between sympatric host races of the leaf beetle Lochmaea capreae. Evolution 70:471-479.

Spady, T. C., O. Seehausen, E. R. Loew, R. C. Jordan, T. D. Kocher, and K. L. Carleton. 2005. Adaptive molecular evolution in the opsin genes of rapidly speciating cichlid species. Molecular Biology and Evolution 22:1412-1422.

Terai, Y., O. Seehausen, T. Sasaki, K. Takahashi, S. Mizoiri, T. Sugawara, T. Sato, et al. 2006. Divergent selection on opsins drives incipient speciation in Lake Victoria cichlids. PLoS Biology 4:2244-2251.

Tezuka, A., S. Kasagi, C. van Oosterhout, M. McMullan, W. M. Iwasaki, D. Kasai, M. Yamamichi, H. Innan, S. Kawamura, and M. Kawata. 2014. Divergent selection for opsin gene variation in guppy (Poecilia reticulata) populations of Trinidad and Tobago. Heredity 113:381-389.

Torres-Dowdall, J., F. Henning, K. R. Elmer, and A. Meyer. 2015. Ecological and lineage-specific factors drive the molecular evolu- 
tion of rhodopsin in cichlid fishes. Molecular Biology and Evolution 32:2876-2882.

Van der Meer, H. J. 1993. Light-induced modulation of retinal development in the cichlid fish Haplochromis sauvagei (Pfeffer, 1896). Zoological Journal of the Linnean Society 108:271-285.

Van der Sluijs, I., T. J. M. Van Dooren, O. Seehausen, and J. J. M. Van Alphen. 2008. A test of fitness consequences of hybridization in sibling species of Lake Victoria cichlid fish. Journal of Evolutionary Biology 21:480-491.

Volpato, G., and R. Barreto. 2001. Environmental blue light prevents stress in the fish Nile tilapia. Brazilian Journal of Medical and Biological Research 34:1041-1045.

Wagner, C. E., L. J. Harmon, and O. Seehausen. 2012. Ecological opportunity and sexual selection together predict adaptive radiation. Nature 487:366-370.
Weadick, C. J., E. R. Loew, F. H. Rodd, and B. S. W. Chang. 2012 Visual pigment molecular evolution in the Trinidadian pike cichlid (Crenicichla frenata): a less colorful world for Neotropical cichlids? Molecular Biology and Evolution 29:3045-3060.

Westley, P. A. H., E. J. Ward, and I. A. Fleming. 2013. Fine-scale local adaptation in an invasive freshwater fish has evolved in contemporary time. Proceedings of the Roval Societv B 280: 20122327.

White, E. M., S. C. Church, L. J. Willoughby, S. J. Hudson, and J. C. Partridge. 2005. Spectral irradiance and foraging efficiency in the guppy, Poecilia reticulata. Animal Behaviour 69:519-527.

Associate Editor: Rebecca C. Fuller Editor: Judith L. Bronstein

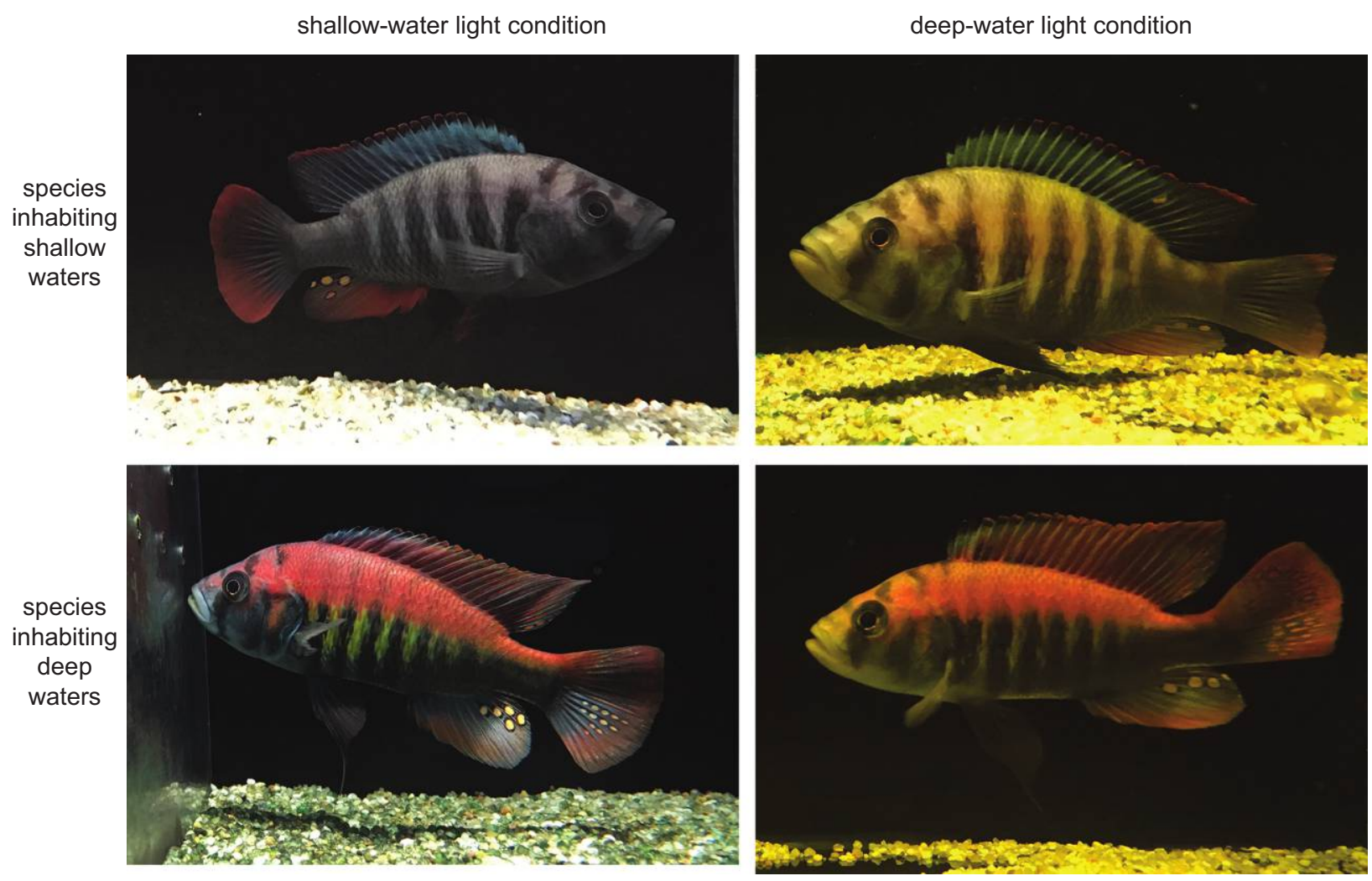

Males in manipulated light treatments-Pundamilia pundamilia (full brothers; top) and Pundamilia nyererei (full brothers; bottom) in shallow (left) and deep (right) light conditions. Photos by D. Shane Wright. 